\title{
Quantifying Disease in Challenging Conditions: Incidence and Prevalence of Rheumatoid Arthritis
}
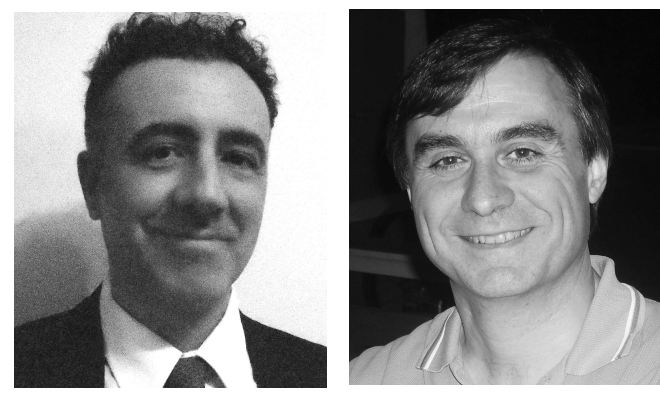

Prevalence and incidence are both key measures in decision-making processes and in healthcare management in general. While prevalence informs about the probability of being ill, incidence is related to the probability of becoming sick: Both are very relevant estimates of the frequency of a disease.

Available data on the prevalence and incidence of rheumatoid arthritis (RA) display high variability among different geographic areas and over time $e^{1,2,3,4,5,6,7}$. This variability cannot be explained only by genetic factors; other environmental and epigenetic conditions may also influence these figures. Besides, some methodological aspects in the determination of these frequencies might have a strong influence on the informed rates.

The annual incidence rates of RA range from 20 to 50 per 100,000 inhabitants in North American and Northern European countries $8,9,10,11$, while in Southern Europe there is a lower occurrence of the disease ${ }^{12,13,14}$. Besides, incidence seems to be increasing in recent years in some countries after a drop during the last decade of the 20th century. In South America, 1 study carried out in Argentina and published in 2003 reported an incidence rate of 24.5 per 100,000 inhabitants ${ }^{15}$.

Many population-based studies have shown a prevalence rate of RA close to $1 \%$ (UK, USA, Lithuania). Again, some important differences among countries have been noted. Scandinavian and Mediterranean countries seem to display lower rates, between $0.18 \%$ and $0.92 \%$. Conversely, higher rates were reported from regions near the Arctic. Three previous studies on the prevalence of RA carried out in Argentina, based on the American College of Rheumatology (ACR) 1987 criteria, reported rates of $0.24,0.19$, and 0.94 , respectively ${ }^{15,16,17}$; some of the discrepancies among them might be explained by intracountry regional differences. Nevertheless, underreporting may be another important methodological aspect to consider in the analysis of these differences.

With the aim of minimizing underreporting, cap- ture-recapture models have been used to estimate incidence and prevalence of many diseases and health-related problems ${ }^{17}$. This approach derives the size of the source population from the number of individuals "captured" by 2 (or more) independent samplings of this population. As an example, medical registries of RA cases that include only patients with a condition diagnosed and followed up by rheumatologists, but not those assessed by general practitioners or orthopedists, may lead to underestimation. To overcome this limitation, a telephone survey may be carried out as a secondary source of cases to get a capture-recapture based estimate. Capture-recapture methods are based on 2 assumptions: (1) there is no dependency among all the sources of information in the model, and (2) all the individuals have the same probability of being captured. Neither of the 2 assumptions can usually be directly tested, and violations in these assumptions may result in overestimation or underestimation of the studied frequency rates.

Another methodological source of variation is related to diagnostic criteria. The 2010 ACR/European League Against Rheumatism classification criteria for RA delivered a new definition for the disease. These criteria improve sensitivity (mainly in early stages of the disease), with a reduction in specificity. More patients are diagnosed as compared with the ACR 1987 criteria. While the 1987 criteria seem to be based on longterm damage, the 2010 criteria point out the acute inflammatory components of the disease ${ }^{18}$. As expected, the between-study comparisons are affected as the disease definition differs. This aspect emphasizes the fact that the lack of a gold standard continues to be an obstacle in the estimation of both incidence and prevalence rates for RA.

To the best of our knowledge, the study by Di, et al ${ }^{19}$ is the first to provide an estimate of the incidence of RA as defined by the 2010 ACR/European League Against Rheumatism (EULAR) criteria in a Latin American city (Buenos Aires, Argentina). The authors obtained global and age- and sex-specific incidence and prevalence rates, using

See Epidemiology of RA in Argentina, page 1306

Personal non-commercial use only. The Journal of Rheumatology Copyright @ 2016 . All rights reserved. 
data from a university hospital-based health management organization. By applying a capture-recapture technique, they determined the 2000-2015 incidence rate to be 18.5 cases per 100,000 person-years; the prevalence was $0.329 \%$ by January $2015^{19}$. In the retrospective calculation of incidence, changes in the diagnostic methods lead to a biased estimator: by 2000 , anticitrullinated protein antibodies (ACPA) were not part of the regular diagnostic process for RA. Nevertheless, for the Di study, the ACR/EULAR 2010 criteria were used to define the cases required to estimate the incidence rates. Moreover, once installed into the general practice, measurements of ACPA had the common evolution of laboratory methods in longitudinal studies when relatively long terms are involved (in this case, different generations of ELISA kits). Another limitation in applying the 2010 criteria, which was highlighted by Humphreys, et al in the Norfolk study ${ }^{18}$, could also apply to the $\mathrm{Di}$, et al study results: the 2010 criteria include an amendment stating that any patient with radiological evidence of typical RA erosions should be classified as RA (without requirement for any other criteria). Because radiographs were not taken into account in all the sources of this capture-recapture study, the accuracy of the obtained frequencies might have been affected. Besides, it has to be pointed out that there is no clear, unequivocal and universally accepted definition of "typical RA erosion," which seems to be another difficult issue to consider in the evaluation of the accuracy of these disease estimates.

Many of these limitations may affect other epidemiological studies based on the prevalence and incidence of RA; yet these indicators are at the core of our medical decision-making processes. Any good-quality information in the area, even recognizing the above-mentioned methodological concerns, should be more than welcome. This is especially remarkable for emerging/developing countries, where the capabilities for obtaining such information are particularly limited by resources.

It is hoped that greater use of appropriate tools to obtain unbiased, accurate measurement of RA frequency will lead to more effective diagnostic and therapeutic programs in human health worldwide, and particularly in less-developed countries.

\section{DARIO SCUBLINSKY, $\mathrm{MD}, \mathrm{PhD}$,}

Rheumatologist, Professor of Pharmacology, Faculty of Medicine,

National University of Buenos Aires

Buenos Aires, Argentina;

\section{CLAUDIO D. GONZALEZ, $\mathrm{MD}$,}

Professor of Pharmacology, Instituto Universitario CEMIC, Buenos Aires, Argentina.

Address correspondence to Dr. D. Scublinsky, Faculty of Medicine, University of Buenos Aires, Paraguay 2155, 15th Floor, Ciudad de Buenos Aires, Argentina. E-mail: darioscublinsky@yahoo.com.ar

\section{REFERENCES}

1. Hochberg MC. Changes in the incidence and prevalence of rheumatoid arthritis in England and Wales, 1970-1982. Semin Arthritis Rheum 1990;19:294-302.

2. Dugowson CE, Koepsell TD, Voigt LF, Bley L, Nelson JL, Daling JR. Rheumatoid arthritis in women. Incidence rates in group health cooperative, Seattle, Washington, 1987-1989. Arthritis Rheum 1991;34:1502-7.

3. Kaipiainen-Seppanen O, Aho K, Isomaki H, Laakso M. Incidence of rheumatoid arthritis in Finland during 1980-1990. Ann Rheum Dis 1996;55:608-11.

4. Gabriel SE, Crowson CS, O'Fallon WM. The epidemiology of rheumatoid arthritis in Rochester, MN, 1955-1985. Arthritis Rheum 1999;42:415-20.

5. Doran MF, Pond GR, Crowson CS, O'Fallon WM, Gabriel SE. Trends in incidence and mortality in rheumatoid arthritis in Rochester, Minnesota, over a forty-year period. Arthritis Rheum 2002;46:625-31.

6. Helmick CG, Felson DT, Lawrence RC, Gabriel S, Hirsch R, Kwoh $\mathrm{CK}$, et al. Estimates of the prevalence of arthritis and other rheumatic conditions in the United States. Part I. Arthritis Rheum 2008;58:15-25.

7. Myasoedova E, Crowson C, Kremers HM, Therneau TM, Gabriel S. Is the incidence of rheumatoid arthritis rising? Results from Olmsted County, Minnesota, 1955-2007. Arthritis Rheum 2010;62:1576-82.

8. Riise T, Jacobsen BK, Gran JT. Incidence and prevalence of rheumatoid arthritis in the county of Troms, northern Norway. J Rheumatol 2000;27:1386-9.

9. Aho K, Kaipiainen-Seppanen O, Heliovaara M, Klaukka T. Epidemiology of rheumatoid arthritis in Finland. Semin Arthritis Rheum 1998;27:325-34.

10. Symmons DP, Barrett EM, Bankhead CR, Scott DG, Silman AJ. The incidence of rheumatoid arthritis in the United Kingdom: results from the Norfolk Arthritis Register. Br J Rheumatol 1994;33:735-9.

11. Soderlin MK, Borjesson O, Kautiainen H, Skogh T, Leirisalo-Repo M. Annual incidence of inflammatory joint diseases in a population based study in southern Sweden. Ann Rheum Dis 2002;61:911-5.

12. Drosos AA, Alamanos I, Voulgari PV, Psychos DN, Katsaraki A, Papadopoulos I, et al. Epidemiology of adult rheumatoid arthritis in northwest Greece 1987-1995. J Rheumatol 1997;24:2129-33.

13. Guillemin F, Briancon S, Klein JM, Sauleau E, Pourel J. Low incidence of rheumatoid arthritis in France. Scand J Rheumatol 1994;23:264-8.

14. Carbonell J, Cobo T, Balsa A, Descalzo MA, Carmona L; SERAP Study Group. The incidence of rheumatoid arthritis in Spain: results from a nationwide primary care registry. Rheumatology 2008;47:1088-92.

15. Soriano ER, Carrio JH, Schpilberg M, Figar S, Imamura PM, Catoggio LJ. Incidence and prevalence of rheumatoid arthritis (RA) in a Health Management Organization (HMO) in Argentina. Rheumatology 2003;42:363A.

16. Spindler A, Bellomio V, Berman A, Lucero E, Baigorria M, Paz S, et al. Prevalence of rheumatoid arthritis in Tucuman, Argentina. J Rheumatol 2002;29:1166-70.

17. Scublinsky D, Venarotti H, Citera G, Messina OD, Scheines E, Gonzalez C, et al. The prevalence of rheumatoid arthritis in Argentina: a capture-recapture study in a city of Buenos Aires province. J Clin Rheumatol 2010;16:317.

18. Humphreys JH, Verstappen SM, Hyrich KL, Chipping JR, Marshall T, Symmons DP. The incidence of rheumatoid arthritis in the UK: comparisons using the 2010 ACR/EULAR classification criteria and the 1987 ACR classification criteria. Results from the Norfolk Arthritis Register. Ann Rheum Dis 2013;72:1315-20.

19. Di WT, Vergara F, Bertiller E, Gallardo ML, Gandino I, Scolnik M, et al. Incidence and prevalence of rheumatoid arthritis in a health management organization in Argentina: a 15-year study. J Rheumatol 2016;43:1306-11.

J Rheumatol 2016;43:1263-4; doi:10.3899/jrheum.160522

Personal non-commercial use only. The Journal of Rheumatology Copyright (C) 2016. All rights reserved 